\title{
PRESCRIPCIÓN Y TÍTULOS EJECUTIVOS, RESPECTO DE LA ACCIÓN CAMBIARIA
}

\author{
Alberto Viada Lozano \\ Profesor de Derecho Comercial \\ Universidad Católica del Norte
}

Se ha discutido en el ámbito judicial, con variadas resoluciones, la circunstancia de poder "revivir" las acciones que naturalmente emergen de los efectos de comercio, especialmente las letras de cambio, pagarés y cheques, después de transcurridos los plazos de prescripción establecidos por las diversas disposiciones legales que los rigen. Más concretamente, existen opiniones controvertidas sobre la posibilidad de crear títulos ejecutivos una vez cumplidos los plazos de prescripción y, por ende, ejercer la acción cambiaría ejecutiva respecto de alguno de dichos documentos, mediante la gestión preparatoria de la vía ejecutiva de reconocimiento de firma y confesión deuda. Las próximas líneas pretenden ser un aporte a esta controversia.

El primer tropiezo para esclarecer el tema proviene de las diversas acepciones del concepto jurídico de "acción", y más específicamente en su vinculación con la institución de la "prescripción". Vemos, por ejemplo, que el artículo 588 del Código Civil señala a la prescripción como un modo de adquirir el dominio, y que, según el artículo 2.517 del mismo Código, esta prescripción adquisitiva extingue la acción por la cual se reclama el mismo derecho. Por otra parte, vemos que, según el articulo 1.567 №10으, las obligaciones se extinguen por la prescripción, pero, de conformidad con los artículos 2.492 y 2.514 , todos del Código Civil, lo que se extingue por la prescripción son las acciones y derechos ajenos. Luego, el artículo 2.515 distingue plazos de prescripción para acciones ejecutivas y ordinarias, introduciendo un elemento procesal en el confuso panorama conceptual en estudio, que nos incita a la perplejidad, al existir prescripciones de corto tiempo inferiores a los plazos señalados en dicho artículo, dejando la duda si en estos casos la acción que prescribiría sería la ejecutiva, la ordinaria o ambas. Asimismo, el №17 del artículo 464 del Código de Procedimiento Civil, al señalar como excepción admisible en el juicio ejecutivo la prescripción de la deuda o sólo de la acción ejecutiva, nos incita a asimilar la prescripción de la deuda a la de la acción ordinaria, sin poder encuadrar las otras acciones que no tengan por objeto una deuda específica, como las acciones de nulidad o las posesorias.

Para dilucidar estas inquietudes, es bueno delimitar el concepto de "acción", para lo cual recurro a la definición de don Fernando Alessandri R., ("Derecho Procesal Civil", Edit. Nascimiento, pág. 52 ), para quien la "acción es la facultad que tiene una persona para ocurrir ante los tribunales de justicia, cuando se le desconoce o viola un derecho que cree tener", o a don Eduardo J. Couture, ("Vocabulario Jurídico" Facultad de Derecho. Montevideo 1960, citado por Roberto Guzmán Santa Cruz en "Repertorio de Conceptos de Derecho Procesal Civil", Edit. Carlos E. Gibbs. Stgo. 1966, pág. 30), que la define: "Derecho abstracto de obrar: poder jurídico que tiene todo sujeto de derecho, consistente en la facultad de acudir ante los órganos de la ju- 
risdicción, exponiendo sus pretensiones y formulando la petición que afirma como correspondiente a su derecho".

En otras palabras, la acción es una sola, consistente en poder acudir a los tribunales de justicia para formular las pretensiones que una persona estime corresponderle. Esta acción no tiene calificativos de ninguna especie, pero al concretarse en una pretensión, ésta la especifica. Así, se denomina acción reivindicatoria la que puede ejercer el dueño no poseedor en contra del poseedor no dueño para que se le restituya la cosa en disputa; acción de petición de herencia la del heredero contra quienes poseyeren dicha herencia como tales para que se le restituyan las cosas hereditarias; acción de restablecimiento la del poseedor para que se restablezca la posesión que le ha sido violentamente arrebatada, etcétera, etcétera, etcétera. $Y$ esta especificación de la acción ha permitido también formular algunas clasificaciones, como acciones reales y personales, según se pretenda el ejercicio de derechos reales o personales; acciones muebles o inmuebles, según la naturaleza del objeto de la pretensión; acciones ordinarias o ejecutivas, según el procedimiento a que se somete la pretensión.

Ahora bien, el titular de un derecho puede ejercer su acción planteando ante los órganos de la jurisdicción la pretensión que corresponde a dicho derecho, normalmente a través de un procedimiento declarativo, para que se le reconozca el derecho y se ordene lo pertinente para su ejercicio. Este ejercicio de la acción, por ser lo normal o usual, recibe el nombre de acción ordinaria, que no significa exclusivamente el empleo del procedimiento del juicio ordinario, sino de aquél que corresponda a la pretensión. Pero, excepcionalmente, el titular del derecho puede contar con alguno de los títulos ejecutivos que la ley reconoce como tales, en cuyo caso puede ejercer la acción ejecutiva. La tenencia de un título ejecutivo no excluye el ejercicio de la acción ordinaria, incluso en muchos casos el título tiene fuerza ejecutiva para exigir el cumplimiento de alguna de las obligaciones del contrato, pero no lo tiene para el ejercicio de otros derechos que, necesariamente, tendrán que ejercerse mediante el procedimiento que corresponda a la pretensión. El ejemplo más usual de ello puede estar en la compraventa de un inmueble, cuya escritura pública constituye titulo ejecutivo para cobrar el precio o exigir la tradición de lo comprado, pero que servirá sólo de medio de prueba para ejercer el derecho a la resolución del contrato con indemnización de perjuicios por incumplimiento de uno de los contratantes. Y el mismo ejemplo sirve para determinar la prescripción de la acción, pues el titular del derecho podrá ejercer la acción ejecutiva dentro de los tres años siguientes a la fecha en que la obligación se hizo exigible, porque si no prescribe esta acción ejecutiva, aunque siempre le quedará a salvo, después de los tres años, el ejercicio de la acción ordinaria derivada del mismo contrato.

De lo expuesto podemos concluir que lo normal es que la prescripción se aplique a la acción ordinaria, con plazos variables, como diez años (petición de herencia, nulidad absoluta), cinco años (norma general), cuatro años (nulidad relativa, contratos mercantiles), dos años (cobro de honorarios), un año (precios al menudeo, posesorias, acción cambiaria), seis meses (acción cambiaria de reembolso), etcétera, y excepcionalmente a las acciones ejecutivas, cuyo plazo de prescripción es de tres años, salvo el caso del cheque que se rige por una norma especial.

Veamos ahora el tema que nos preocupa, pues si la prescripción es un modo de extinguir las acciones y derechos ajenos, por no haberse ejercido dichas acciones y derechos durante cierto lapso de tiempo, concurriendo los demás requisitos legales, y que, 
respecto de los requisitos legales de la prescripción extintiva, se exige solamente cierto lapso de tiempo durante el cual no se hayan ejercido dichas acciones, ¿será posible renovar esos derechos después de transcurrido el plazo de prescripción? Al respecto cabe recordar las normas precisas que fijan los plazos de prescripción de los efectos de comercio materia de este estudio.

En cuanto al cheque, el artículo 34 del Decreto con Fuerza de Ley №707 de 1982, que fijó el texto refundido, coordinado y sistematizado de la Ley Sobre Cuentas Corrientes Bancarias y Cheques, señala que "la acción ejecutiva contra los obligados al pago de un cheque protestado y la acción penal, prescribirán en un año, contado desde la fecha del protesto...". Está claro, entonces, que esta norma se refiere sólo a la acción penal y a la acción ejecutiva, por lo que no es aplicable a la acción ordinaria, y que sólo se refiere a los cheques protestados, pero nada dice de los que no hayan sido objeto de esta diligencia. En consecuencia, para dilucidar cuál sería el plazo de prescripción de la acción ordinaria, debemos recurrir a lo dispuesto en el inciso tercero del artículo 11 de este mismo cuerpo legal, que dice: "El cheque dado en pago se sujetará a las reglas generales de la letra de cambio, salvo lo dispuesto en la presente ley". Como en esta ley sólo se hace referencia a la prescripción de las acciones penales y ejecutivas, nos remitiremos respecto a la acción ordinaria a las normas sobre la letra de cambio.

Respecto al pagaré, el artículo 107 de la Ley 18.092 hace la misma remisión, al disponer que: "en lo que no sean contrarias a su naturaleza y a las disposiciones del presente Título, son aplicables al pagaré las normas relativas a la letra de cambio". O sea, las normas comunes de prescripción de la acción ordinaria proveniente de cheques, pagarés y letras de cambio son las de los artículos 98 y 99 de la ley 18.092, que disponen: "El plazo de prescripción de las acciones cambiarias del portador contra los obligados al pago es de un año, contado desde el día del vencimiento del documento", y "Las acciones de reembolso de que trata el articulo 82 prescriben en el plazo de seis meses contados desde el día del pago cuyo reembolso se reclama".

Entonces, si ha transcurrido el plazo de un año de prescripción de la acción ordinaria, ¿será posible preparar la vía ejecutiva por medio del reconocimiento de firma o confesión de deuda? Existe una posición que niega esta posibilidad y que afirma incluso que el juez, de oficio, podría negarse a despachar el mandamiento de ejecución y embargo, por aplicación del artículo 442 del Código de Procedimiento Civil, que dispone: "El tribunal denegará la ejecución si el título presentado tiene más de tres años, contados desde que la obligación se haya hecho exigible..." Argumentan que este plazo de tres años, concordante con el plazo de prescripción de las acciones ejecutivas establecido en el artículo 2.515 del Código Civil, debe entenderse aplicable sólo a los derechos cuyas acciones ordinarias prescriben en más años que los tres fijados para la ejecutiva, pero que en los casos de plazos de prescripción de la acción ordinaria menores de tres años, como son los de las acciones cambiarias, dichas disposiciones se entenderían tácitamente derogadas, o mejor dicho modificadas, por las leyes dictadas con posterioridad que establecieron esos plazos menores. En otras palabras, la ley 18.092, y todas aquéllas que se remitan a ella, habrían modificado tácitamente los artículos 2.515 y 442 citados, reduciendo a un año, o seis meses si se ejerce la acción de reembolso, el plazo de tres años que en ellas aparece. Incluso, dentro de esta corriente de opinión, hay quienes afirman que el juez podría negarse a dar curso a la gestión preparatoria de la vía ejecutiva, porque igualmente debería con posterioridad negar lugar a la ejecución, por aplicación del artículo 442 tantas veces citado. 
Estimo que estos argumentos no pueden admitirse como válidos, desde que en el mismo Proyecto del Código Civil elaborado por don Andrés Bello se contemplaban, (artículos 720, 724, 725 y 726, hoy 2.515, 2.521 y 2.522 del Código Civil ), plazos de prescripción de acciones ordinarias inferiores al de la acción ejecutiva, y que el propio artículo 442 del Código de Procedimiento Civil limita la posibilidad del tribunal de negar de oficio la ejecución, en los siguientes términos:" . . ; salvo que se compruebe la subsistencia de la acción ejecutiva por alguno de los medios que sirven para deducir esta acción en conformidad al artículo 434,", entre los cuales se cuenta precisamente con el reconocimiento judicial de instrumento privado y la confesión judicial. En otras palabras, desde los inicios de nuestra legislación positiva se contemplaron acciones ordinarias cuyo plazo de prescripción era menor del establecido para la acción ejecutiva, permitiéndose al mismo tiempo que el titular del derecho se proveyera de un título ejecutivo, o renovara el existente, mediante gestiones judiciales preparatorias de la vía ejecutiva.

Otra opinión acepta la confesión de deuda para la formación de un título ejecutivo, una vez cumplido el plazo de prescripción de la acción cambiaria, siempre que dicha confesión se refiera al negocio causal o relación fundamental que originó el efecto de comercio. En estos casos no se trataría de ejercer la acción cambiaria, propia del documento, sino la correspondiente al negocio causal, normalmente con un plazo mayor de prescripción, siendo el efecto de comercio un mero antecedente, un principio de prueba por escrito, que justificaría la gestión preparatoria de la vía ejecutiva del negocio causal. Por ejemplo, con una letra de cambio originada en una compraventa o un mutuo, aunque cumplido el año de prescripción del documento, podría generarse un título ejecutivo para el cobro del precio o la restitución del dinero prestado.

Me parece que no existe ninguna posibilidad de discusión al respecto, puesto que las acciones provenientes del negocio causal no adolecerían de la eventualidad de ser declaradas prescritas. Sin embargo, ello sería posible solamente entre los partícipes de dicha relación fundamental o negocio causal, pero atenta contra la abstracción y autonomía del título de crédito. Estimo que un endosatario de un efecto de comercio, que no participó ni tiene por qué saber de la existencia o naturaleza de la relación fundamental de la que nació el título de crédito, puede también citar a la presencia judicial a cualquiera o todos los obligados al pago del documento, para que reconozcan su firma y confiesen su obligación de pago del mismo, conformando un título ejecutivo con ello, aunque haya transcurrido el plazo de un año que la ley establece para la prescripción de la acción cambiaria.

Sin embargo, ello conllevaría el aparente contrasentido de que, vencido el plazo de la acción ordinaria, pueda intentarse una acción ejecutiva por el simple procedimiento de citar al deudor a reconocer su firma o confesar la deuda. ¿Significaría ello que la prescripción extintiva sería una institución prácticamente inoperante? Lo cierto es que, en mi opinión, lejos de hacerla inoperante, resulta ser una aplicación cabal de todos los principios que informan la prescripción. Veamos:

Lo primero que debemos aclarar es que la prescripción no opera de pleno derecho, sino que debe ser judicialmente declarada. O sea, aunque se hayan cumplido todos los presupuestos jurídicos para que opere la prescripción, especialmente el transcurso del plazo, la acción no estará prescrita mientras no exista una sentencia judicial, firme o ejecutoriada, que así lo declare. 
En segundo término cabe señalar que, conforme a las claras disposiciones del artículo 2.493 del Código Civil, "el juez no puede declararla de oficio".

Por último, y en mi concepto el factor más importante a considerar, "la prescripción puede ser renunciada expresa o tácitamente", como meridianamente lo reconoce el artículo 2.494 , que no es más que la aplicación específica del principio sustentado en el artículo 12, ambos del Código Civil. Como muy bien aclara la primera disposición citada, la renuncia de la prescripción, sea expresa o tácita, procede "sólo después de cumplida", no es admisible la renuncia anticipada, y "no puede renunciar la prescripción sino el que puede enajenar", como lo advierte el artículo 2.495 del mismo cuerpo legal.

Entonces, con un efecto de comercio respecto del cual ha transcurrido el plazo legal de un año para la prescripción de la acción ordinaria, o sea "después de cumplida", el tenedor del documento puede citar a la presencia judicial a cualquiera de los obligados a su pago, a fin de establecer si renuncia o no a la prescripción que lo favorece. Sabemos que se renuncia tácitamente a la prescripción "cuando el que puede alegarla manifiesta por un hecho suyo que reconoce el derecho del acreedor". Y también sabemos que, si el acreedor "quiere preparar la ejecución por el reconocimiento de firma o por la confesión de la deuda, podrá pedir que se cite al deudor a la presencia judicial, a fin de que practique la que corresponda de estas diligencias". "Y, si el citado no comparece, o sólo da respuestas evasivas, se dará por reconocida la firma o por confesada la deuda". (Arts. 2494 inc. $2^{\circ}$ del C. Civil y 435 del de P. Civil).

El obligado al pago del documento, que no puede alegar ignorancia de la ley, puede adoptar diversas actitudes ante esta citación para preparar la vía ejecutiva. La primera de ellas es concurrir al tribunal y negar su firma y la deuda. En estas circunstancias no habrá título ejecutivo y el tenedor determinará si intenta ejercer su acción en un procedimiento ordinario, en donde el demandado podrá oponer la prescripción en cualquier estado del juicio, antes de la citación para sentencia en primera instancia o de la vista de la causa en segunda.

Otra actitud, de mayor frecuencia, es concurrir y reconocer la firma pero negar la deuda. En este caso queda preparada la ejecución, pero al ejecutado le quedará a salvo la excepción de prescripción de la deuda, contemplada en el №17 del articulo 464 del Código de Procedimiento Civil, que deberá plantearla en la única oportunidad procesal que existe para ello, so pena de ser declarada inadmisible.

Una tercera actitud es comparecer y reconocer la firma y confesar la deuda. De esta forma, el que puede aprovecharse de la prescripción, una vez cumplida, renuncia expresamente a ella y confiesa que está obligado a pagar la deuda, lo que se obtendrá en el procedimiento ejecutivo consecuente.

Una última actitud es la de no comparecer, con lo que el juez dará por reconocida la firma y por confesada la deuda. En mi opinión, éste es un ejemplo de renuncia tácita a la prescripción, puesto que el demandado, conocedor de que su inasistencia acarrea la confesión de la deuda, omite asistir, produciéndose un hecho suyo que reconoce el derecho del acreedor. De este modo, entiendo que, en el juicio ejecutivo consecuente, si opusiere la excepción de prescripción, ella no prosperaría, puesto que ya habría renunciado tácitamente a ella, al no concurrir a la citación judicial y permitir que se le tuviera por confeso de la deuda. 
Creo conveniente reiterar que lo que implica una renuncia, expresa o tácita,- a la prescripción extintiva de la acción, es la confesión judicial, puesto que el reconocimiento de firma, si bien deja preparada la ejecución, también deja a salvo la excepción de prescripción, que sólo podrá plantearse en la única oportunidad procesal que contempla el juicio ejecutivo. Sin embargo, si el ejecutado no opone oportunamente dicha excepción, como el que quiera aprovecharse de la prescripción debe alegarla, al no hacerlo en la actuación procesal determinada que establece la ley, ello también debe entenderse como una renuncia tácita.

Cabe concluir, entonces, que nuestra legislación contempla expresamente la posibilidad de configurar un título ejecutivo, mediante el reconocimiento de firma y confesión de deuda, respecto de los efectos de comercio en que el plazo de prescripción de la acción ordinaria se encuentra cumplido, constituyendo la confesión judicial de la deuda una renuncia a la prescripción y quedando a salvo el derecho a oponer esta excepción si se configura el título ejecutivo solamente con el reconocimiento de firma. 